
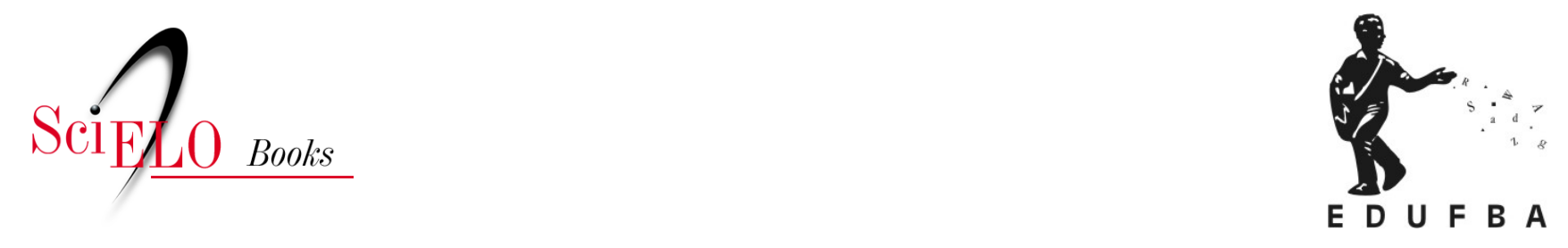

\title{
Condições de trabalho e riscos em uma central de regulação médica de urgência o caso dos técnicos auxiliares de regulação médica - TARM
}

\author{
Tarciso de Figueiredo Palma \\ Paulo Gilvane Lopes Pena \\ Rita de Cássia Pereira Fernandes
}

\section{SciELO Books / SciELO Livros / SciELO Libros}

PALMA, T.F., PENA, P.G.L., and FERNANDES, R.C.P. Condições de trabalho e riscos em uma central de regulação médica de urgência: o caso dos técnicos auxiliares de regulação médica - TARM. In: LIMA, M.A.G., FREITAS, M.C.S., PENA, P.G.L., and TRAD, S., orgs. Estudos de saúde, ambiente e trabalho: aspectos socioculturais [online]. Salvador: EDUFBA, 2017, pp. 53-77. ISBN: 978-85-232-1864-5. http://doi.org/10.7476/9788523218645.0004

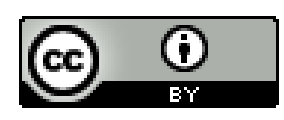

All the contents of this work, except where otherwise noted, is licensed under a Creative Commons Attribution $\underline{4.0 \text { International license. }}$

Todo o conteúdo deste trabalho, exceto quando houver ressalva, é publicado sob a licença Creative Commons Atribição 4.0. 


\title{
Condições de trabalho e riscos em uma central de
} regulação médica de urgência o caso dos técnicos auxiliares de regulação médica - TARM

\author{
TARCISO DE FIGUEIREDO PALMA \\ PAULO GILVANE LOPES PENA \\ RITA DE CÁSSIA PEREIRA FERNANDES
}

\section{Introdução}

Os call centers podem ser definidos como unidades de produção do serviço de telemarketing. (VENCO, 2006) O telemarketing, como o próprio termo indica, é o marketing realizado à distância por meio do uso de técnicas de telecomunicações, principalmente o telefone, e mais recentemente a telemática, ao associar sistemas informáticos. Nesse sentido, o seu uso intenso requer a formação de centrais telefônicas conceituadas como: “[...] fábricas de comunicação e gestão de informação que nascem dos processos de flexibilização do trabalho e digitalização das tecnologias de informação e comunicação”. (THIRIÓN, 2007, p. 49, tradução nossa) Uma característica que deu forma a essa nova tendência foi a economia de tempo para o cliente e a redução das distâncias. (ASSUNÇÃO; SOUZA, 200o) 
Segundo dados da Associação Brasileira de Telesserviços, no início de 2008, com 750 mil trabalhadores, essas empresas se transformaram no maior empregador na área de serviços. (ABT, 2011) Atualmente se tem um panorama de mais de um milhão de trabalhadores neste ramo produtivo. (ABT, 2011) Há, no entanto, call centers que não são de telemarketing propriamente dito, e que foram incorporados a esse contexto de trabalho. Segundo o Ministério do Trabalho e Emprego, o telemarketing se subdivide em segmentos e, dentre esses, existe aquele que presta assistência técnica e especializada aos usuários do sistema de saúde e aciona serviços emergenciais (BRASIL, 2010), onde se enquadram as centrais de regulação médica do Serviço de Atendimento Móvel de Urgência (SAMU) 192, locus desse estudo.

O interesse no estudo do trabalho em um call center de saúde pública advém de suas características e sua relevância, pois além do teleatendimento ser um dos setores que mais emprega no Brasil, a sua organização do trabalho pressupõe diferentes modalidades de controle dos mecanismos laborais do trabalhador, onde suas diversas consequências, principalmente nos aspectos relacionados à saúde desse trabalhador, alimentam diferentes estigmas à profissão. (RICCI; RACHID, 2013) Soma-se a isso o crescente uso do call center nos serviços públicos em todas as esferas de atenção, proporcionando relação direta entre o modo de organização do trabalho no teleatendimento e a efetividade da atenção prestada, especialmente nos casos de urgência e emergência, cuja repercussão negativa pode ser fatal ou incapacitante para o usuário. São exemplos as aplicações públicas bastante conhecidas, como: Corpo de Bombeiros 193, Polícia Militar 190 e o próprio Samu 192. Muito se discute atualmente sobre as relações da organização do trabalho em call centers e a saúde de seus trabalhadores. Os modos operacionais tayloristas são reorganizados no processo de reestruturação produtiva, com suporte de novas tecnologias, e aprofundam o aperfeiçoamento do controle sobre os movimentos e a produtividade, constituindo-se em modalidades neotayloristas de organização do trabalho. (OLIVEIRA; JACQUES, 2006; VENCO, 2006)

Venco (2006) mostra em seu estudo formas de adoecimento, como Lesões por Esforço Repetitivo (LER), inscritas em ambiente de grande pressão provocado pelo estresse nesses trabalhadores. Esse modelo neotaylorista moderno, oferece à gestão mecanismos mais precisos no pro- 
cesso de supervisão, que perpassam, desde dados estatísticos sobre produtividade de cada teleoperador, à escuta da conversa on time entre este e um cliente, orientados por novas tecnologias de inteligência artificial ou robótica virtual. Conforme demonstra Calderón (2006) e Boutet (2006), o teleoperador precisa seguir rotinas linguísticas pré-concebidas que são repetitivas e que causam descontentamento e estresse. Essa "modernização” das relações de poder, segundo Assunção e seus colaboradores (2006, p. 55) “[...] representa, muitas vezes, uma forma mais facilmente perceptível de pressão pelo seu caráter coercitivo, carregando grande potencial adoecedor”.

Em relação às novas tecnologias que dão suporte às modalidades de controle e intensificação do trabalho, os sistemas computacionais e respectivos softwares se destacam como paradigma essencial na análise do trabalho. Essas novas tecnologias virtuais dão suporte à gestão do processo de trabalho, oferecendo o controle e automação da sua produção, bem como auxilia nas decisões. Tais técnicas de inteligência artificial são definidas como softwares permeados pela linguagem matemática com algoritmo binário, ou um conjunto de instruções, que em execução produzem a função desejada. (REZENDE, 2005)

Segundo Abrahão, Silvino e Sarmet (2005), a emergência de uma abordagem distinta nos processos de informatização do trabalho é salientada por diversos autores que apontam que se deve considerar como fontes de subsídios dos projetos de sistemas informatizados a pesquisa em situação real, verificando a compatibilidade cognitiva entre a representação das estruturas do sistema e as do usuário, obtendo a compreensão das situações em que os sistemas serão aplicados, sua compatibilidade com os processos decisórios envolvidos e as estratégias dos usuários.

Nesse contexto, esse estudo teve como objetivo analisar o trabalho, o uso de softwares de gestão e suas condições de risco à saúde, a partir da ocupação específica de Técnico Auxiliar em Regulação Médica (TARM).

\section{Métodos}

Esse estudo foi realizado em um call center de uma central de regulação médica do Samu 192 na Bahia, utilizando uma abordagem metodológica baseada na pesquisa qualitativa com suporte da Análise Ergonômica do Trabalho(AET). 
Deacordo coma AET, as condições de trabalho resultam da inter-relação complexa dos múltiplos fatores constituintes da situação de trabalho, dos meios disponíveis para a execução das tarefas, dos objetivos postos pela organização do trabalho a serem cumpridos pelo trabalhador e das condições objetivas e subjetivas de cada sujeito que trabalha, em cada momento de seu processo. A escolha desta abordagem visa evidenciar as condições nas quais um importante serviço de utilidade pública é desenvolvido. (GUÉRIN et al., 2001; LIMA, 200o) A investigação teve o apoio de uma central municipal de regulação médica do Samu 192 na Bahia, junto ao corpo de trabalhadores teleoperadores, entre os meses de abril e setembro de 2010. Foi aprovada pelo Comitê de Ética em Pesquisa da Secretaria de Saúde do Estado da Bahia (SESAB).

O quadro de funcionários do Samu 192, desde a central de regulação em todos os turnos aos trabalhadores das unidades móveis (ambulâncias), conta com 103 profissionais por turno de plantão, totalizando 748 trabalhadores. Os sujeitos da pesquisa, os TARMs, representam a maioria dentro da central de regulação, num total de 14 profissionais por turno. (BAHIA, 2010) Doze TARMs participaram voluntariamente da pesquisa, sendo que apenas sete foram entrevistados individualmente. Vale salientar que os nomes dos trabalhadores relacionados nos extratos de narrativas descritos nos resultados são todos fictícios com o objetivo de preservar o sigilo, atendendo aos preceitos éticos da pesquisa com seres humanos.

O presente estudo teve início com uma exploração do funcionamento de um call center do Samu 192. Nesta etapa, procedeu-se a reunião documental e sua leitura, seguida de observações livres. Para a identificação das tarefas e atividade de trabalho foram planejadas e realizadas as observações sistemáticas inscritas em diário de campo. Foram registradas as verbalizações espontâneas dos teleoperadores em situação de trabalho e realizadas entrevistas semiestruturadas, consecutivas ao trabalho, como técnica complementar às observações. O material produzido nessas entrevistas semiestruturadas foi submetido à análise das narrativas propostas por Minayo (2010).

Dessa forma, o estudo baseou-se na abordagem da Análise Ergonômica do Trabalho (AET). Segundo Palácios, Duarte e Câmara (2002, p. 845):

Essa estratégia de investigação possui a vantagem de oferecer maior possibilidade de apreender as situações, identificando seus elementos, colocando-os em relação uns com os outros, 
compreendendo como são construídas as situações e como se desenvolvem em seu movimento próprio.

A situação de trabalho, longe de ter uma característica estável, é marcada pela variabilidade, seja do sistema sociotécnico, seja dos sujeitos que trabalham. Para essa perspectiva da análise situada do trabalho há contextos de trabalho e sujeitos em atividade em relação dinâmica.

A AET compartilha os princípios gerais da abordagem etnográfica como estratégia de estudo, e utiliza como técnica de estudo a observação participante, com a particularidade de incluir a entrevista em autoconfrontação. (DANIELLOU, 2004; GUÉRIN et al., 2001; LIMA, 2000; WISNER, 1994, 1996)

As primeiras observações duraram 19 horas e foram feitas em sete dias diferentes, com 15 horas durante o dia e quatro horas durante a madrugada. Após esse momento, foram realizadas as entrevistas durante turnos de atendimento real. Foram realizadas sete entrevistas, com dois homens e cinco mulheres, num total de 13 horas e 15 minutos. Todos os registros dos ciclos, com número de toques, Tempo Médio de Atendimento (TMA) e frequência de situações foram feitos através de anotações em diário de campo.

Uma vez estruturadas as informações sobre o funcionamento do Samu e sua capacidade instalada, destacou-se inicialmente os fatos relevantes da organização e gestão do trabalho. Registrou-se, em seguida, as principais tarefas, suas exigências, habilidades requeridas, perturbações observadas, comportamentos e verbalizações recorrentes relativas a cada atendimento realizado. Destacou-se também as características comuns aos atendimentos básicos, e as variabilidades decorrentes da regulação das perturbações, que interferiam diretamente no tempo do atendimento. Buscou-se identificar, em situação de trabalho, as ações dos TARMs em face à variabilidade do sistema de trabalho. Ou seja, procurou-se evidenciar o que está além do prescrito nas normas do serviço, conforme indica a AET. (GUÉRIN et al., 2001) A análise considerou o caráter individual e compartilhado do trabalho em equipe no SAMU.

Com o decorrer da pesquisa foram elucidadas questões, e através da imersão no universo empírico resultante das observações e das entrevistas, o trabalho prescrito foi confrontado com o que ocorria, o trabalho real. As reflexões geradas por meio desse confronto se concentraram na identificação de contradições entre a norma e as demandas reais postas aos trabalhadores, permitindo constituir categorias de análises das situações que representassem o real do trabalho dos TARMs. 


\section{Resultados e discussão}

A ação de atendimento do SAMU se inicia por meio de uma chamada telefônica de um usuário dos serviços de saúde. Todos os chamados de urgência feitos para o telefone 192 são direcionados ao call center do SAMU 192, que é uma central de regulação médica. Para atender à demanda da população, essa central deve seguir diretrizes básicas de atendimento, que, segundo o Ministério da Saúde (BRASIL, 2004), são: atender aos chamados telefônicos 24 horas sem interrupção; garantir o acesso do paciente à unidade de saúde - pronto atendimento, pronto socorro, hospital geral ou especializado -, conforme sua necessidade; acompanhar a situação das unidades de urgência; verificar se essas estão com muitos casos para atender; garantir que as equipes médicas estejam completas; conferir se existem leitos vagos; avaliar a situação das UTI's e dos equipamentos para diagnóstico.

O regime de contratação dos funcionários do SAMU estudado é feito por meio do Regime Especial de Direito Administrativo (REDA), definido a partir de Termo de Ajuste de Conduta (TAC) determinado pelo Ministério Público do Trabalho. As categorias ocupacionais de atendimento são o TARM: profissional de nível básico que atende por meio de telefone à demanda da população, preenchendo informações básicas sobre a ocorrência e prestando informações gerais. Sua atuação é supervisionada diretamente e permanentemente pelo médico regulador. Outras categorias ocupacionais são: rádio operador $(\mathrm{RO})$, médico regulador e monitor.

Quanto à jornada de trabalho, o TARM e RO têm escalas de seis horas diárias, com descanso de 20 minutos, enquanto que os médicos reguladores cumprem plantões de 12 horas com descanso de uma hora, folgando por três dias (24 horas semanais). Todos têm possibilidade de dobrar a escala.

\section{Sobre o técnico auxiliar em regulação médica e suas tarefas}

Embora alguns TARM tenham cinco anos na função, o perfil desses profissionais não difere do encontrado nos demais call centers. (ABT, 2011) Em sua maioria são jovens, entre 18 e 35 anos, com predominância de mulheres. Além da inserção no SAMU, em turnos de trabalho de seis horas, muitos deles têm outro emprego ou estudam. A função de TARM se realiza 
como uma porta de entrada do usuário ao sistema de saúde, a um serviço de urgência médica.

A urgência se dá em forma de chamado telefônico atendido primeiramente pelo TARM. Este classifica o tipo de ligação: orientação, engano, trote e urgência com ou sem disparo automático da ambulância. Em seguida ele dá continuidade ao atendimento de forma a conduzir o mais rápido possível seu desfecho.

O TMA varia dependendo das demandas ao TARM, isso porque ele pode, ao mesmo tempo em que preenche um formulário eletrônico, questionar o solicitante, variando então em função do tipo de chamada. Quando o chamado transcorre sem maiores intercorrências, e se trata de caso de urgência, esse dura em média de um minuto e trinta segundos a três minutos.

Em alguns casos especiais, a abertura de uma ocorrência pode durar até mais de seis minutos. Esse ciclo mais longo é gerado a partir da gravidade da ocorrência e da dificuldade de comunicação do solicitante, submetido, na maioria das vezes, aos estressores presentes em uma situação que envolve a urgência médica ou risco de vida para outrem. Conseguir a coleta das informações necessárias para otimizar o tempo de atendimento e manter o solicitante capaz de seguir com as futuras orientações do médico regulador é tarefa posta ao TARM.

Após classificar o tipo do chamado e preencher o sistema com informações iniciais, o TARM repassa a ligação ao médico regulador que faz o atendimento preliminar e também preenche o sistema com informações pertinentes. Em seguida, o médico regulador, munido de um pré-diagnóstico, entra em contato com a rádio operação, que encaminha ou não uma unidade de saúde - a ambulância - para o local da ocorrência.

As tarefas e operações nas quais o TARM está envolvido são expressas da seguinte forma: o solicitante do serviço entra em contato com o SAMU 192 em forma de chamado telefônico, que é atendido pelo TARM, seu primeiro interlocutor. Este segue um ciclo de atendimento, com um TMA, dependente da modalidade da chamada. O TARM pode encerrar a ligação se constatar trote, contato não pertinente ao SAMU, ou engano. Caso o chamado seja pertinente, o TARM então dá continuidade ao atendimento, conforme organograma funcional na Figura 1. 


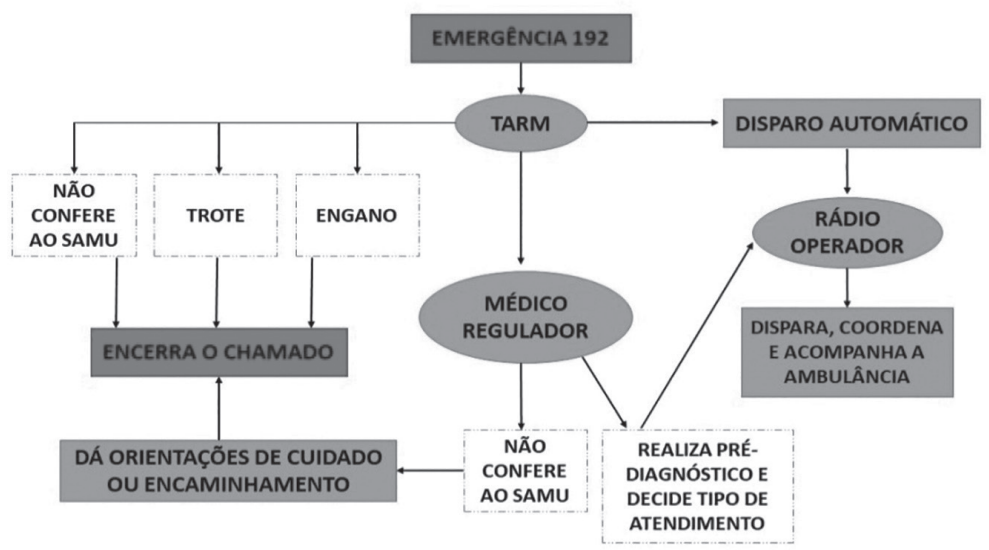

Fonte: elaborada pelos autores.

A partir daí surgem diversas situações. Serão descritas, a seguir, situações que contemplam quase a totalidade dos tipos de chamadas “entrantes”, como trotes, chamadas por engano, para pedido de orientação e as chamadas de urgência. Essas situações estruturais das tarefas do TARM representam as categorias consideradas para a análise do trabalho.

\section{O teletrote $\mathbf{e} 0$ atendimento de urgência}

Nos períodos de elevado fluxo de entrada de chamadas, como final da manhã e final da tarde, essas totalizaram aproximadamente 70 chamadas, entre enganos, trotes, interrupções de ordem técnica e chamadas reais, das quais foram registrados entre 35 e 45 ciclos de trote, no intervalo de uma hora. "Foram 2486! É demais! A tarde toda ligando, você desliga e ele liga de novo... isso irrita demais, e fora que congestiona a linha, tem gente precisando de atendimento e não consegue contato...”. (Armando)

Na figura 2 encontra-se descrito o fluxo do atendimento do TARM centrado no caso do trote, desde o recebimento da chamada, seus desdobramentos, até ao posicionamento final com a definição da existência ou não de trote. O ciclo para um atendimento de chamada considerada que trote, basicamente, dura entre 12 e 23 segundos. Não se pretende contemplar a variabilidade dessa situação neste fluxograma, porém ele exemplifica o processo básico. 
Figura 2 - Fluxograma de procedimentos implementados pelo técnico auxiliar de regulação médica para identificação do trote

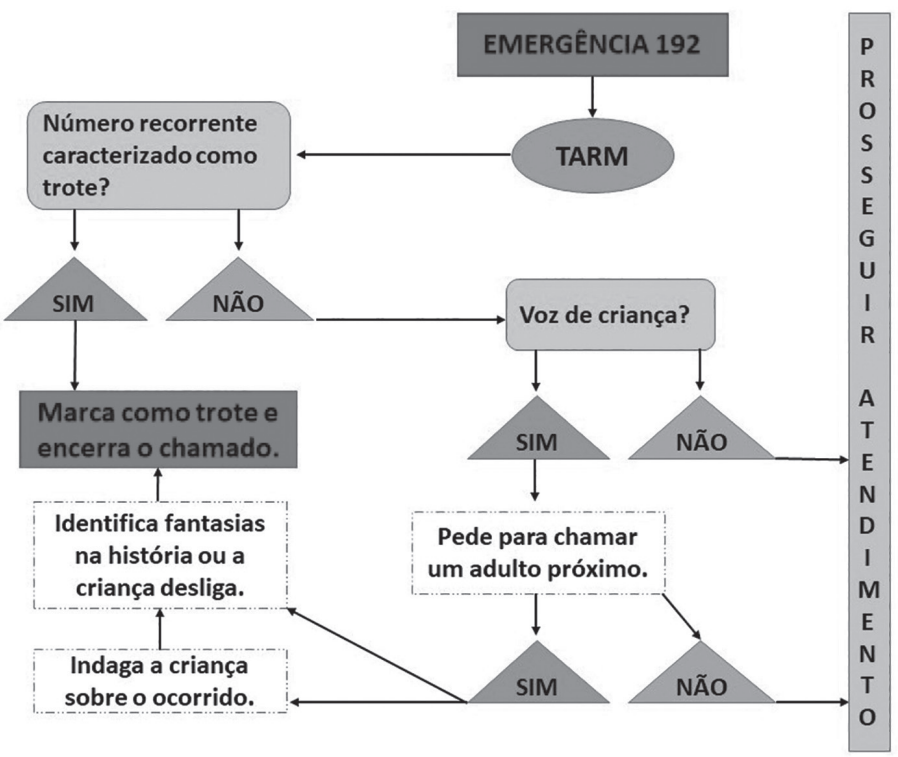

Fonte: elaborada pelos autores.

Na medida em que o fluxo desses trotes aumenta, a tarefa se torna repetitiva, com ciclos curtos, conforme números apresentados anteriormente. A automação pelo software ainda não permite a quebra dessa repetitividade, através da qual, ligações com números recorrentes classificados como trote seriam automaticamente informadas com alertas.

Segundo a percepção dos TARM, os trotes chegam à elevada proporção de $60 \%$. No histórico das ligações, verificou-se que um mesmo número telefônico originou mais de 3 mil ligações caracterizadas como trote.

No Brasil, os serviços públicos de urgência, como Polícia Militar (190), Corpo de Bombeiros (193), além do SAMU (192), como descrito, são acometidos diariamente por essa prática, em que o fluxo de tais ligações alcança aproximadamente $40 \%$ da demanda em algumas regiões. (ANDRADE et al., 2010) Nos estudos de Castro e colaboradores (2006) foi encontrada a alarmante proporção de $42 \%$ de trotes nestes serviços. No Rio de Janeiro, o trote para serviços de urgência é considerado crime, resultando em ressarcimento dos custos do serviço do autor, bem como detenção e multa. (RIO DE JANEIRO, 2012) 
Apesar de representar uma grande exigência de trabalho, verifica-se o paradoxo de não existir protocolo pré-estabelecido de identificação do trote. O software do SAMU, - programa de computador que gere os atendimentos - apesar de contemplar a opção TROTE, oferece apenas o reconhecimento do número de telefone como sendo recorrente e classificado anteriormente como trote, mas não oferece apoio à tomada de decisão. $\mathrm{O}$ cancelamento da chamada é de responsabilidade do TARM e isto gera tensão, devido às consequências de um possível engano, conforme expresso na fala: "Na maioria das vezes a gente acerta. Mas pode ser que dê errado! Aí...”. (Flor)

Para constatar um trote, o TARM utiliza sua experiência no processo de identificação. De uma forma geral, quando o chamado é de criança, em sua grande maioria, caracteriza-se como trote. A experiência é fator importante, principalmente quando o trabalhador recorre à memória de situações análogas para a compreensão de certas situações. (GUÉRIN et al., 2001) Segundo Abrahão e Torres (2004, p. 69), a representação quando associada à ação se refere "[...] às redes de propriedades, de conceitos, de saberes, de habilidades, de crenças e de experiências construídas no decorrer da história do indivíduo, a partir da sua relação com o trabalho”, e que são convocadas em situações nas quais a memória é requerida para viabilizar a ação. $\mathrm{O}$ recurso às experiências vividas previamente é o principal mecanismo utilizado pelo TARM para identificar o trote, conforme verbalizações dispostas a seguir. Caso haja erro, esse profissional assume a responsabilidade das consequências.

Na relação entre usuário e operador de call center, Svensson (2012) revela influências psicoafetivas nos processos de tomada de decisão, porém estabelece uma simbiose em dois sistemas distintos para processamento da informação. O primeiro sistema, qualificado como racional, tem características cognitivas, geralmente mais lento no processo tempo-resposta, demanda algum esforço, é norteado por regras pré-definidas, porém com alguma flexibilidade e neutralidade. Enquanto que o segundo sistema é majoritariamente comandado por afeto, de natureza pré-consciente, rápido, automático, não verbal, e também associado a processos intuitivos. Esses dois sistemas trabalham de forma independente, mas podem também dialogar entre si, ou seja, apresentam características interativas e uso de condutas centradas na linguagem. 
Diante de possível trote, o TARM se depara com situações que são identificadas nessa transversalidade revelada nesses dois sistemas para processamento da informação. No exemplo de chamadas feitas por crianças, a experiência do profissional, mesmo sem suporte do software ou de protocolos específicos, indica o trote. Entretanto, em situações de chamadas verdadeiras, contrariando o padrão, a caracterização errada como trote causa comoção no trabalhador, além da repercussão no quadro do paciente.

Você vê logo, quando é voz de criança: '- moço, moço, está pegando fogo aqui...'; você vê que éuma brincadeira. (Chaves)

Tem chamado que a gente não percebe logo de cara. Aí com o tempo, perguntando uma coisa num momento, repetindo a pergunta em outro, a pessoa se contradiz. Tem gente que não aguenta, pede para sair. Isso cansa mesmo! É pressão! (Armando)

Tal situação gera conflitos, pois para o usuário existe a possibilidade de lidar com a desconfiança do seu atendente (TARM) e isso pode resultar em outra fonte de estresse. Enquanto que para o TARM, apesar de todas as indicações para $o$ ato de trote, existe a possibilidade de ser realmente uma urgência, conflito que o acompanha do início ao final de seu turno. O TARM tem o poder de decidir e isso significa assumir o risco. Conviver com essa contradição causa tensão. Trazendo o que discutem Abrahão e Torres (2004), a propósito das exigências do atendimento em outro call center, o trote, comum nesta central, aumenta a carga de trabalho, pois exige dos TARM maior habilidade na comunicação, manutenção da paciência e da cordialidade em situações que podem ser críticas, adotando estratégias para evitar o fracasso resultante de uma decisão errada.

Para Pascale Molinier (2004), a psicodinâmica do trabalho considera que quando a organização das atividades impossibilita a transformação do sofrimento em prazer, realizações e suporte pessoal, então tal trabalho se torna prejudicial à saúde mental. Situações como essa foram observadas e verbalizadas pelos TARM diante de conflitos entre a tentativa de transformação do trabalho em realizações como estratégia de defesa e equilíbrio, salvando vidas e melhorando o cuidado com o paciente, e a anulação dessa possibilidade condicionada pelas pressões organizacionais limitantes, que geram riscos operacionais capazes de resultar em vivências psíquicas dramáticas, com estresse excessivo associado à conduta equivocada. 
O trote, junto às ligações por engano e orientação somam aproximadamente $70 \%$ da demanda de trabalho do TARM. Todo o complexo de decisões nesse leque se concentra na experiência do TARM, profissão essa sem plano de carreira pública adicionada a alto turnover. Essa condição é pouco considerada nas soluções técnicas e sociais para melhoria simultânea das condições de trabalho e da efetividade do atendimento do SAMU.

\section{O desconhecimento público para o uso do atendimento de urgência}

Além dos trotes, os enganos, pedidos de orientações e chamadas de urgência completam em quase sua totalidade as ocorrências para o SAMU 192. Os enganos podem chegar a aproximadamente $10 \%$, ou mais, das chamadas por hora, e exigem do TARM elaborar uma resposta que auxilie o solicitante, ainda que esta não seja uma tarefa prevista, para a qual o TARM não dispõe de qualquer dispositivo no sistema operacional. Esta situação pode ser evidenciada por meio da seguinte fala: “Ó senhora, já que ele não tá sentindo nada, isso não é para o SAMU, a senhora liga 156, que é do serviço 'X', que é para a população de rua....'. (Flor)

Ao lado das chamadas classificadas como trote, os enganos representam um fluxo expressivo do total geral de ligações e condiciona o congestionamento das linhas telefônicas. Para tratamento dessa demanda incorreta, como no caso citado acima, o software não oferece links com chamadas automáticas para outros call centers, como o do "X", Polícia Militar, Corpo de Bombeiros, entre outros. O tempo despendido nesse processo de atendimento e elaboração de uma resposta favorece o congestionamento das linhas telefônicas e, sobretudo, a sobrecarga psíquica ao exigir o recurso à memória dos operadores.

Em uma perspectiva ampliada, constata-se que não há campanhas educativas para a população em geral, com o objetivo de elucidar questões, como o propósito do SAMU 192 e a importância de solicitar o serviço corretamente. Nesse sentido, Paiva e Avelar (2011) reiteram essa necessidade de melhoria no que tange à ampliação do conhecimento da população a respeito dos serviços de saúde, em especial das funções fundamentais do SAMU 192 no âmbito do Sistema Único de Saúde (SUS). 


\section{A chamada de urgência: insuficiência dos meios e saber-fazer}

Quando a chamada é uma urgência, o TARM pode ter duas ações principais: anotar todos os dados preliminares e passar para o médico regulador para que esse faça o encaminhamento da unidade de atendimento para a ocorrência, via rádio operador, caso julgue necessário; ou, dependendo da gravidade, o próprio TARM faz o "disparo” automático da unidade de atendimento sem passar pelo médico regulador. O TARM segue um protocolo, instituído pelos médicos como eventos de maior urgência, que o autoriza a "disparar" uma ambulância antes de passar o chamado ao médico. Entretanto, não foi evidenciado no sistema utilizado pelos TARM estruturas que gerissem tal situação.

O ciclo de um atendimento de urgência com ou sem disparo automático é o mesmo em termos de dados digitados e duração do contato do usuário com o TARM - média de dois minutos. Na situação de disparo automático, em vez do TARM passar a chamada ao médico regulador e este coordenar o rádio operador para enviar uma unidade de atendimento, a requisição da ambulância é realizada pelo próprio TARM logo nos primeiros segundos do contato.

No cadastro das ocorrências, o TARM precisa navegar por algumas telas e identificar, em meio a muitos campos, o correto local para digitar as informações do paciente. Nesta tela se exige maior tempo de navegação e susceptibilidade a erros sistêmicos, relatados como comuns: "Esse negócio de estar entrando em janela e caindo [...], acho que o sistema deveria ter uma tela só". (Chaves)

O sistema informatizado, ferramenta utilizada pelos TARM, foi concebido sem a participação do trabalhador. Desta forma, constatou-se que não se contempla características de segurança e funcionalidade requeridos na execução das etapas de trabalho dos TARM. Assim, é evidenciada a incompatibilidade entre a ferramenta disponível - software - e as exigências das tarefas. Nos dizeres dos TARM: “Tem dia que enche. [...] Entra barra de rolagem. [...] que cansa...”. (Chaves) “Atender toda hora apertando o botão...” (Evaneide)

É notória a exclusão do trabalhador no processo de construção de sua ferramenta, confirmada nas incoerências sistêmicas presentes nas interfaces do software. A exemplo, o caso da densidade informacional ou na ausência de recursos que apoiassem o trabalhador a tomar decisões diante de situações como a do disparo automático. 
No disparo automático, o erro acontece com frequência, pois os TARM, muitas vezes, enviam desnecessariamente mais de uma unidade móvel para a mesma ocorrência, haja vista os casos de disparo automático requererem pressa devido sua maior urgência. A escolha é do TARM de "errar por excesso", uma vez que a incerteza habita sua decisão e o compromisso de cuidar da vida assume prioridade.

Teve uma colisão, vítima nas ferragens e tal... Não é nem uma nem duas pessoas que vão ligar, são várias, existem muitas portas de entrada. A gente manda muito duas unidades pra uma ocorrência só. [...] Eu mando as duas, eu vou errar pra menos? Eu vou errar pra mais, né? É uma coisa que fica a critério da gente, se for errar pra menos meu irmão... (pausa) Se for uma pessoa que esteja ali numa necessidade, você pode comprometer a vida de uma pessoa. (Chaves)

Não existe na interface do sistema uma estrutura que contemple tal situação, sobrecarregando o trabalhador, que, por conseguinte, quando erra sobrecarrega o sistema de saúde como um todo.

Porém a principal sobrecarga do TARM, conforme a análise permitiu evidenciar, é de ordem psicoafetiva, segundo relatos e situações já mostrados envolvendo o contexto relacional no cuidado com a saúde, e nas ações que envolvem salvar uma vida. Além disso, há exigência de ordem cognitiva, pelo recurso rápido à memória e uso do software.

O próprio software, que em determinados momentos evidencia a sua insuficiência, pode também ser utilizado numa perspectiva de proteção ao seu operador. Segundo Abrahão, Silvino e Sarmet (2005, p. 163) "a dialética entre usabilidade e navegabilidade permite a (re)concepção por meio da lógica de quem usa, ao invés da lógica de quem concebe”, ou seja, o trabalhador deveria ter papel central no processo de reengenharia de sua ferramenta de trabalho. Essa estratégia metodológica está na essência no uso do método ergonômico de análise do trabalho, contudo, geralmente não tem sido objeto de consideração. Sobre isso, Kafure (2010) demonstra a eficácia do uso da ergonomia em concepção com o usuário, participando desde as etapas iniciais do processo. A autora afirma que o sistema, o software, é conhecido muitas vezes pelo operador quando já está em funcionamento, e isso pode ocasionar dificuldades diversas que são derivadas da discrepância, entre as expectativas e necessidades do operador, definidas pelo trabalho real e as tarefas pré-dispostas nas interfaces. 
Evidencia-se na observação e verbalizações, a insuficiência do software quanto aos seus recursos, gerando sobrecarga psíquica e agravando ainda mais as condições estressantes de trabalho.

\section{Salvar vidas: entre o sofrimento e a satisfação}

Constatou-se a satisfação dos TARM em estar desempenhando um trabalho nobre, o de ajudar a salvar vidas. Este aspecto pode representar um efeito de proteção da saúde mental do trabalhador. A satisfação encontra-se no plano individual e na esfera da intersubjetividade que leva a reforçar as ações, mesmo diante de dificuldades no cotidiano. Essa satisfação "refere-se à integração, à autonomia, à motivação, ao envolvimento e à utilização das capacidades físicas e mentais”. (MARQUEZE; MORENO, 2005) "Eu acho que estar lidando diretamente com o salvamento é uma coisa que estimula muito”. (Dr ${ }^{\mathrm{a}}$. Vanessa)

A capacidade de enfrentamento das situações nocivas, dentre elas a submissão a sistemas de inteligência artificial, pode ser percebida pelo trabalhador como fonte de sofrimento, no entanto, a subversão das normas, o uso de sua expertise diante da variabilidade do trabalho, também podem representar a sublimação desse sofrimento, trazendo algum prazer, como uma gratificação psíquica ao trabalhador. (OLIVEIRA; REZENDE; BRITO, 2006; TORRES; ABRAHÃO, 2006)

[...] Tirando o estresse, quando você vê o resultado do trabalho... É gratificante saber que o seu trabalho ajuda as pessoas. (Dudu)

Tem esse lado que é importante também. A responsabilidade de estar lidando com isso. É interessante. É bem importante mesmo. Eu não tinha essa visão antes e agora... Só passa a admirar depois que conhece o trabalho, ofuncionamento, é bem gratificante, às vezes, ver a ocorrência que você abriu e que no final deu tudo certo, que a pessoa está bem. (Evaneide)

Notou-se que o reconhecimento da importância das ações desses trabalhadores por parte dos seus superiores, como também da população em geral, pôde ter resultados positivos. Porém, mais importante do que o reconhecimento alheio é a percepção de que os trabalhadores apresentam sua importância e seu valor para esse trabalho. Isso certamente reforça um sentido de dignidade e felicidade ao desempenhar suas atividades, o que pode 
significar uma defesa para sua saúde psíquica e um estímulo que proporcionam satisfação no trabalho, sendo, segundo Marqueze e Moreno (2005), influência inegável no processo saúde-doença.

Apesar do esforço empreendido em um atendimento, no qual vidas serão ou foram salvas, constatou-se a indisponibilidade de informação sobre o percurso terapêutico seguido pela vítima após o atendimento do TARM que abriu o chamado. Isso consolida a fragmentação do cuidado e do caráter pontual do vínculo estabelecido pelo TARM com o solicitante. É possível que a incorporação de resultados sobre este percurso seguinte do paciente, no próprio software, pudesse significar uma compensação e reconhecimento do trabalho do TARM. Exaltar-se-iam os aspectos positivos do trabalho, fortalecendo a autoestima do trabalhador que lida diariamente com a importante missão de salvar vidas em uma sociedade com elevados índices de violência.

\section{Batismo ocupacional: estratégia coletiva de defesa?}

Outra característica do trabalho do TARM se relaciona com a sua apresentação ao solicitante. Ele, como todos os profissionais em teleatendimento, segue um padrão de recepção com frases prontas, seguindo um script. (ASSUNÇÃO; SOUZA, 20oo) No caso do SAMU, o TARM se apresenta falando o nome do serviço, seguido do seu nome, cumprimento e pergunta sobre a urgência: "SAMU 192, Flor, bom dia, qual a sua urgência?”.

Questionados se eles estavam seguindo alguma recomendação, ou se usar pseudônimo era alguma norma daquele call center, todos responderam afirmativamente. Aprenderam com os colegas. Alguns nem se recordavam de quando começaram a utilizar esse artifício, que aparentemente representa um ritual de batismo, simbolicamente identificado na escolha de um novo nome.

Meu nome é Júlia, mas a maioria das pessoas aqui usa pseudônimo. E quando eu cheguei aqui já tinha uma pessoa que atendia como Júlia, aí eu bolei um nome (começou a rir) que fica fácil de eu lembrar [...]. É assim, eu nem sei por quê. Quando eu cheguei já era assim, tem gente que usa o próprio nome e tem gente que usa o nome que gostaria de usar. (Flor) 
Evidencia-se a presença do medo. Nesse caso, trata-se do risco de erro e de sofrer alguma consequência por ato do usuário do SUS contra sua integridade, contra sua vida, ou mesmo o medo da perda do emprego. Dessa forma, esse ritual não prescrito de batismo constitui uma nova identidade que preserva situações temerosas e protege $o$ trabalhador das ameaças.

Essa representação introduz uma identidade virtual, uma espécie de avatar, e se reflete no universo subjetivo do trabalhador, que busca mecanismos para anular o risco, seja simplesmente o ignorando ou o assumindo e buscando estratégias para sua autodefesa. Como todos praticam essa conduta, caracteriza-se então uma intersubjetividade típica de estratégia coletiva de defesa. (DEJOURS, 1991) Na medida em que o trabalhador tem a consciência de que esse risco se relaciona ao trabalho, que é compartilhado por seus pares, o sofrimento deixa de ser individual e as estratégias de defesa geram sentimento de cumplicidade protetora, explicada pela psicodinâmica do trabalho. Nota-se que durante a etapa de campo da pesquisa não se observou nenhum trabalhador utilizar o verdadeiro nome, porém isto pode eventualmente ocorrer.

Esta experiência no trabalho real vivida no SAMU já se encontra contemplada, do ponto de vista das normas de Estado. Indica-se que "as prescrições de diálogos de trabalho não devem exigir que o trabalhador forneça o sobrenome aos clientes, visando resguardar sua privacidade e segurança pessoal”. (BRASIL, 2007, p. [5]) A análise do trabalho revelou tal situação e mostrou sua importância e caráter singular. Essa questão ainda requer maiores discussões e estudos acerca da proteção dos trabalhadores de um lado e da adequada assistência à saúde dos usuários de outro, observando preceitos éticos que envolvem a ação de cuidar da saúde.

\section{Meio ambiente de trabalho, organização e condições de saúde}

Apesar da pouca expressividade do assunto constatada nas narrativas, o relato de casos de adoecimento emergiu das verbalizações dos trabalhadores:

Tive aquela síndrome de Burnout, que é aquela doença ocupacional que é do estresse de exaustão, e aí eu fiquei 15 dias afastada. (Dra. Vanessa) 
Sinto-me estressadíssima... fisicamente sinto muita dor, dor no corpo, eu estava com a cabeça estourando [...] de vez em quando eu sinto uma dor no ombro, nos ombros. (Flor)

As chamadas “dobras”, ou horas extras dobrando a jornada, são frequentes:

Nunca senti nada depois de um dia de trabalho, só estresse mesmo, não tem como, principalmente eu que dou 24 horas, antigamente podia dar 1000 horas, uma vez eu dei 72 horas. (Chaves)

É estressante esse trabalho, porque ficar 6 horas num telefone que não pára nunca... Seis horas na teoria. (Helena)

A fadiga e o estresse são expressos nas narrativas dos trabalhadores:

Cansaço psicológico! Tem dias que o plantão aqui é um pouco estressante, tem paciente que já te atende te xingando; a médica tá cheia de ocorrência e já reclama com a gente, então. (Dudu)

O conflito ilustrado no extrato da narrativa anterior trata do relacionamento entre o TARM e o Médico Regulador. Isto ocorre quando este se sente sobrecarregado de ligações encaminhadas seletivamente pelo TARM, enquanto outros médicos, no mesmo turno, não se disponibilizam para o trabalho. Esta situação desencadeia acusações e repreensões ao TARM, que evita responder ao médico e utiliza o silêncio como estratégia tanto do ambiente quanto do head-set, que podem estar associados a alterações somáticas, cefaleias, zumbidos nos ouvidos, seguidos de vertigens e náuseas.

Outra dificuldade encontrada pelo trabalhador é a de assumir uma doença, pois isso implica assumir um risco quanto à manutenção do emprego.

Porque se a gente assume, entra pra lista de corte, é uma questão de sobrevivência... Qualquer coisa eu digo que é TPM [...] eu já vi gente aqui ficando tempo longe por causa de inflamação no ouvido. LER, teve uma colega nossa aqui que pegou. (Helena)

Demandas excessivas de ordem psíquica, como conflitos originários do trote, revelam uma organização do trabalho com riscos para a saúde do trabalhador. Nesse sentido, a central de regulação médica do SAMU 192 não se distancia muito das outras centrais de teleatendimento quando se trata das possibilidades de adoecimento. 
Outra característica considerada nociva ao trabalhador foi a constatação do uso frequente das “dobras”. A NR 17 e o Artigo 61 da Consolidação das Leis do Trabalho (CLT) trazem que o prolongamento do horário só pode acontecer em casos excepcionais sem ultrapassar às 36 horas semanais previstas. (BRASIL, 2007)

Os trabalhadores na Central de Regulação Médica do SAMU 192 se declaram, em geral, saudáveis. Relatam que foram poucos os casos de afastamento por doenças relacionadas ao trabalho. O SAMU tem menos de seis anos de funcionamento e muitos trabalhadores têm relativamente pouco tempo de trabalho na instituição.

A demanda de tempo para o trabalho em call centers, de modo geral, é definida pela produtividade em função do lucro, com características de uma organização de trabalho taylorista-fordista. (MOCELIN; SILVA, 2008) Porém, no caso do Samu, em função de pertencer à estrutura de serviço do SUS, esse mesmo tempo que dita o trabalho, representa a vida ou a morte de outro. $\mathrm{O}$ ritmo de trabalho não é definido pelo capital, mas sim pela função pública de proteção à saúde como dever do estado.

Insere-se neste bojo uma questão paradoxal, segundo Jackson Filho e Assunção (2006, p. [2]), em que “[...] as formas de organização existentes nos serviços de teleatendimento, cujos modos de gestão são voltados para impedir o desenvolvimento da inteligência, da emoção, da sociabilidade humanas em atividades de trabalho" se contrapõem às próprias características desse trabalho, onde o teleatendente, ou TARM, necessariamente tem na interação humana característica sine qua non no seu contexto laboral. As tarefas inscritas na organização do trabalho do TARM estão pautadas em regras do trabalho encontradas nos serviços de telemarketing em geral, a exemplo do controle rígido de tempo, porém apresentam particularidades e condutas flexíveis. Entretanto, nesse contexto persistem excessos de cargas de trabalho e situações conflituosas internas ao serviço e na relação com usuário que se configuram em riscos à saúde.

A presença do controle comportamental em função das emoções foi uma condição latente nos resultados das observações. Esse controle é de natureza pessoal, condicionado pelo sistema técnico e pela delicadeza da demanda de situação de urgência. Significa que o TARM deve conter, expressar ou eliminar emoções em cada caso atendido, conforme observado nas verbalizações: "Esse me chamou de lerda! Vamos ver o que será que temos 
mais para hoje”. (Flor) É competência do TARM também intervir no quadro emocional do solicitante, de modo a gerir simultaneamente sua própria emoção e a do usuário, enquanto instrumento de trabalho, semelhante ao verificado em outros serviços de telemarketing. (PENA; CARDIM; ARAÚJO, 2011)

Ainda sobre aspectos emocionais, Vilela e Assunção (2004, p. 1071) afirmam que "[...] a natureza da atividade solicita habilidade em contornar situações difíceis e inusitadas [...]”. Por tais razões indicam as necessárias pausas quando momentos de conflito acontecem, sendo ele participante do conflito ou mediador, o que é constante em sua função. A NR 17, anexo II, garante ao trabalhador um tempo para que ele se recupere e consiga socializar os conflitos que porventura possam vir a ocorrer, como ameaças, abuso verbal, agressões, ou situações desgastantes. (BRASIL, 2007)

\section{Considerações finais}

Por meio deste estudo, foi possível conhecer o trabalho em uma central de regulação médica do SAMU 192. Através de uma perspectiva centrada no trabalho do TARM foram desvendadas e descritas as relações existentes, desmistificando algumas situações, e revelando estratégias adotadas pelos trabalhadores para viabilizar a execução das suas tarefas, como as adotadas para identificação do trote e o disparo automático nas urgências. Os ciclos de atendimento do TARM e sua interação com os usuários do serviço evidenciaram alta demanda de trote, sobrecarregando o trabalhador; além das chamadas por engano ou para orientação. Esta sobrecarga pode trazer consequência para a saúde do trabalhador e distanciam o esforço institucional do objeto de ação do serviço de urgência. Descortinou-se ainda uma modalidade de batismo cibernético com o uso de pseudônimo como estratégia de proteção coletiva diante da possibilidade de violência de usuário descontente. Essas condições presentes nas novas práticas da modalidade da telemedicina tornaram-se conhecidas a partir da análise realizada que permitiu conhecer melhor essa realidade pouco estudada.

A melhoria do software pode ser central para redução do desgaste dos TARM. Tal ferramenta poderia contemplar um sistema interativo de alertas ao trote, evitar o excesso de procedimentos repetitivos na jornada, melhorando sua navegabilidade, dentre outras modalidades similares, além de 
sugestões de pausas para descanso ou recuperação, principalmente após chamadas mais demandantes dos aspectos emocionais do trabalhador. Para isso, a participação do trabalhador no processo de reengenharia dessa ferramenta é imprescindível.

Além das medidas técnicas relacionadas aos fundamentos ergonômicos aplicados às pessoas que utilizam o sistema informático, em se tratando do trote, percebe-se a necessidade de ampliar ações para campanhas educativas junto à população, informando sobre as repercussões e desdobramentos desse tipo de acometimento e prejuízos de ordem material e humana. A constituição de legislação específica envolvendo medidas disciplinadoras e punitivas tem sido uma tendência que pode complementar a redução desse fenômeno social perverso.

Apesar das limitações metodológicas e da necessidade de novos estudos sobre o call center em serviços públicos como o SAMU, o presente estudo indicou aspectos críticos da organização do trabalho por meio das observações e expressos nas narrativas. Nesse contexto, a satisfação do trabalhador com a tarefa do cuidado e atendimento à urgência aparece como uma possível proteção, amenizando os efeitos das condições laborais decorrentes da produção de um serviço pautada pela tensão ao lidar com situações delicadas e limítrofes entre vida ou morte dos usuários do sistema SUS.

A melhoria nas condições gerais de trabalho destes profissionais beneficiará sua saúde e possibilitará o crescimento da qualidade no atendimento ao usuário do SUS, que pode se refletir em aumento da eficiência dos atendimentos, salvando mais vidas.

\section{Referências}

ABRAHÃO, J. I.; SILVINO, A. M. D.; SARMET, M. M. Ergonomia, cognição e trabalho informatizado. Psicologia: teoria e pesquisa, Brasília, v. 21, n. 2, p.163-171, maio/ago. 2005 .

ABRAHÃO, J. I.; TORRES, C. C. Entre a organização do trabalho e o sofrimento: o papel de mediação da atividade. Revista Produção, São Paulo, v. 14, n. 3, p. 67-76, set./dez. 2004 .

ANDRADE, A. P. et al. Perfil da assistência do serviço de atendimento móvel de urgência no ano de 2008 no município de Sobral, Ceará. SANARE: Revista de Políticas Públicas, Sobral, v. 9, n. 1, p. 61-63, jan./jun. 2010. 
ASSOCIAÇÃO BRASILEIRA DE TELESSERVIÇOS - ABT. Página de abertura. 2011. Disponível em: <http://www.abt.org.br>. Acesso em: 5 fev. 2011.

ASSUNÇÃO, A. A. et al. Abordar o trabalho para compreender e transformar as condições de adoecimento na categoria dos teleatendentes no Brasil. Revista Brasileira de Saúde Ocupacional, São Paulo, v.31, n. 114, p. 47-62, jul./dez. 2006. Disponível em: <http://www.scielo.br/pdf/rbso/v31n114/o5.pdf>. Acesso em: 5 jan. 2011.

ASSUNÇÃO, A. A.; SOUZA, R. J. Telemática. São Paulo: INST/CUT, 200. (Cadernos de Saúde do Trabalhador).

BAHIA. Secretaria de Saúde do Estado da Bahia. Regula Saúde: projeto de reorganização do atendimento de Urgências e emergências para o estado da Bahia. Salvador, 2010.

BOUTET, J. A atividade do trabalho nas centrais de atendimento: um trabalho de linguagem. Revista Brasileira de Saúde Ocupacional, São Paulo, v. 31, n. 114, p. 73-82, jul./dez. 2006.

BRASIL. Decreto-Lei n ${ }^{\circ} 5 \cdot 45^{2}$, de $1^{\circ}$ maio de 1943. Aprova a Consolidação das Leis do Trabalho. Diário Oficial [da] República Federativa do Brasil, Brasília, DF, 1943. Disponível em: <https://www.planalto.gov.br/ccivil_o3/decreto-lei/ Del5452.htm>. Acesso em: 5 ago. 2010.

BRASIL. Ministério da Saúde. Portaria n 2.657, de 16 de dezembro de 2004. Estabelece as atribuições das centrais de regulação médica de urgências e o dimensionamento técnico para a estruturação e operacionalização das Centrais SAMU-192. Diário Oficial [da] República Federativa do Brasil, Brasília, DF, 2004. Disponível em: <http://bvsms.saude.gov.br/bvs/saudelegis/gm/2004/ prt2657_16_12_2004.html>. Acesso em: o8 dez.2017.

BRASIL. Ministério do Trabalho e Emprego. Anexo II da NR-17. Estabelece parâmetros mínimos para o trabalho em atividades de teleatendimento/ telemarketing nas diversas modalidades desse serviço, de modo a proporcionar um máximo de conforto, segurança, saúde e desempenho eficiente. Diário Oficial [da] República Federativa do Brasil, Brasília, DF, 2007. Disponível em: <http:// trabalho.gov.br/images/Documentos/SST/NR/NR17-ANEXO2.pdf>. Acesso em: 13 dez. 2017.

BRASIL. Ministério do Trabalho e Emprego. CBO - Classificação Brasileira de Ocupações. 2010. Disponível em: < http://www.mtecbo.gov.br/cbosite/pages/ home.jsf $>$. Acesso em: 5 ago. 2010. 
CALDERÓN, J. A. El sentido de lo público en el trabajo a prueba de la restructuración productiva: el caso de los centros de llamadas. Revista Brasileira de Saúde Ocupacional, São Paulo, v. 31, n. 114, p. 19-34, jul./dez. 2006.

CASTRO, I. S. et al. Diferenças interindividuais em teleatendimento de emergências: explicitação por meio da entrevista de autoconfrontação. Revista Brasileira de Saúde Ocupacional, São Paulo, v. 31, n. 114, p. 83-96, jul./dez. 2006.

DANIELLOU, F. (Coord.). A ergonomia em busca de seus princípios: debates epistemológicos. São Paulo: Edgard Blücher, 2004.

DEJOURS, C. A loucura do trabalho: estudo de psicopatologia do trabalho. 4. ed. São Paulo: Cortez, 1991.

GUÉRIN, F. et al. Compreender o trabalho para transformá-lo: a prática da ergonomia. São Paulo: Blucher, 2001.

JACKSON FILHO, J. M.; ASSUNÇÃO, A. A. Trabalho em teleatendimento e problemas de saúde. Revista Brasileira de Saúde Ocupacional, São Paulo, v. 31, n. 114, p. 19-34, jul./dez. 2006. Disponível em: <http://www.redalyc.org/articulo. oa? $\mathrm{id}=100517072001>$. Acesso em: 13 dez. 2017.

KAFURE, I. El proceso creativo de la interfaz del sistema de gestión de la información. Revista Interamericana de Bibliotecología, Medellín, vol. 33, n. 1., p, 169-186, enero/jun. 2010. Disponível em: <http://repositorio.unb.br/ handle/10482/5865>. Acesso em: 5 ago. 2010.

LIMA, F. P. A. A ergonomia como instrumento de segurança e melhoria das condições de trabalho. In: SIMPÓSIO BRASILEIRO SOBRE ERGONOMIA E SEGURANÇA DO TRABALHO FLORESTAL E AGRÍCOLA (ERGOFLOR), 1., 200o, Belo Horizonte. Anais... Viçosa: Universidade Federal de Viçosa, 200o. p. 1-11.

MARQUEZE, E. C.; MORENO, C. R. C. Satisfação no trabalho - uma breve revisão. Revista Brasileira de Saúde Ocupacional, São Paulo, v. 3o, n. 112, p. 69-79, jul./dez. 2005. Disponível em: <http://www.scielo.br/pdf/rbso/v3on112/o7.pdf>. Acesso em: 5 ago. 2010.

MINAYO, M. C. S. O desafio do conhecimento: pesquisa qualitativa em saúde. 12. ed. São Paulo: Hucitec, 2010.

MOCELIN, D. G; SILVA, L. F. S. C. O telemarketing e o perfil sócio-ocupacional dos empregados em call centers. Caderno CRH, Salvador, v. 21, n. 53, p. 365-387, maio/ago. 2008 .

MOLINIER, P. Psicodinâmica do trabalho e relações sociais de sexo: um itinerário interdisciplinar: 1988-2002. Revista Produção, v. 14, n.3, p.14-26, set./ dez. 2004. 
OLIVEIRA, S.; JACQUES, M. G. C. Políticas e práticas de gestão e saúde: recortes sobre o trabalho de teleatendimento no Rio Grande do Sul. Revista Brasileira de Saúde Ocupacional, São Paulo, v.31, n.114, p. 63-72, jul./dez. 2006.

OLIVEIRA, S.; REZENDE, M. S.; BRITO, J. Saberes e estratégias dos operadores de telemarketing frente às adversidades do trabalho. Revista Brasileira de Saúde Ocupacional, São Paulo, v. 31, n. 114, p. 125-134, jul./dez. 2006.

PAIVA, K. C. M.; AVELAR, V. L. L. M. Qualidade de vida no trabalho em uma central de regulação médica de um serviço de atendimento móvel de urgência (SAMU). Organizações e Sociedade, Salvador, v. 18, n. 57, p. 303-321, abr./jun. 2011.

PALÁCIOS, M.; DUARTE, F.; CÂMARA, V. M. Trabalho e sofrimento psíquico de caixas de agências bancárias na cidade do Rio de Janeiro. Cadernos de Saúde Pública, Rio de Janeiro, v. 18, n.3, p. 843-851, maio/jun. 2002.

PARAGUAY, A. I. B. B. Da organização do trabalho e seus impactos sobre a saúde dos trabalhadores. In: MENDES, R. (Org.). Patologia do Trabalho. 2. ed. São Paulo: Atheneu, 2005. p. 811-823.

PENA, P. G. L.; CARDIM, A.; ARAÚJO, M. P. N. Taylorismo cibernético e lesões por esforços repetitivos em operadores de telemarketing em Salvador-Bahia. Caderno CRH, Salvador, v. 24, p. 131-153, 2011. Suplemento 1.

REZENDE, D. A. Engenharia de software e sistemas de informação. 3. ed. Rio de Janeiro: Brasport, 2005.

RICCI, M. G.; RACHID, A. A organização do trabalho em serviços: um estudo sobre o teleatendimento. Revista Eletrônica Produção \& Engenharia, Juiz de Fora, v. 3, n. 1, p. 224-235, jan./jun. 2013 .

RIO DE JANEIRO (Estado). Assembleia Legislativa. Projeto de Lei $n^{\circ}$ 1483/2012. Dispõe sobre medidas contra a prática de trotes telefônicos dirigidos aos órgãos que especifica. 2012. Disponível em: <http://alerjln1.alerj.rj.gov.br/scpro1115.nsf/ dde654f2fb348o6783256ceeoo589oed/bdg6f3bbef859444832579eboo64993f?O penDocument\&ExpandSection=-1>. Acesso em: 5 maio 2013 .

SVENSSON, M. Routes, routines and emotions in decision making of emergency call takers. 2012.355 f. Dissertation (Doctoral in Industrial Economics and Management) - School of Management, Blekinge Institute of Technology, Sweden, 2012. (Blekinge Institute of Technology doctoral dissertation series, $\mathrm{n}$. 2012:04).

THIRIÓN, J. M. Los call centers y los nuevos trabajos del siglo XXI. CONfines de relaciones internacionales y ciencia política, Nuevo León, v. 3, n. 5, p. 49-58, enero/ mayo 2007 . 
TORRES, C. C.; ABRAHÃO, J. I. A atividade de teleatendimento: uma análise das fontes de prazer e sofrimento no trabalho. Revista Brasileira de Saúde Ocupacional, São Paulo, v. 31, n. 114, p. 113-124, jul./dez. 2006.

VENCO, S. Centrais de atendimento: a fábrica do século XIX nos serviços do século XXI. Revista Brasileira de Saúde Ocupacional, São Paulo, v.31, n. 114, p.7-18, jul./dez. 2006.

VILELA, L. V. O.; ASSUNÇÃO, A. A. Os mecanismos de controle da atividade no setor de teleatendimento e as queixas de cansaço e esgotamento dos trabalhadores. Cadernos de Saúde Pública, Rio de Janeiro, v. 2o, n. 4, p. 1069-1078, jul./ago. 2004 .

WISNER, A. A inteligência no trabalho: textos selecionados de ergonomia. Tradução de Roberto Leal Ferreira. São Paulo: FUNDACENTRO, 1994.

WISNER, A. Atividades humanas previstas, atividades humanas reais nos sistemas automatizados. In: SEMINÁRIO INTERINSTITUCIONAL “TRABALHO, TECNOLOGIA \& ORGANIZAÇÃO”, 1., 1996, Belo Horizonte. Anais... Belo Horizonte: UFMG: Escola de Engenharia, 1996. p. 1-16. 